\title{
Bronchial carcinoid with massive ossification: A case report and review of literature
}

\author{
Mohamed Khalil, Mahmoud Eltorky \\ Department of Pathology, University of Texas Medical Branch, Galveston, Texas, USA
}

Received November 28, 2015; Revised May 31, 2016; Accepted May 31, 2016; Published Online June 19, 2016

\section{Case Report}

\begin{abstract}
We report a case of a 47-year-old male with unexplained fatigue, shortness of breath, fever, chronic cough, and weight loss of over 12 pounds over a 3 months period. Chest x-ray revealed complete opacification of the right hemithorax with collapse of the right middle and lower lung lobes and midline shift towards the right. A CT scan with contrast showed a $6 \mathrm{~cm}$ mass arising from the right mainstem bronchus that was completely occluding the lumen, causing right lung atelectasis. Histopathologic examination of the tumor revealed an atypical carcinoid tumor with massive ossification. This is a case report and review of the literature of the rare bronchial carcinoid demonstrating bone formation.
\end{abstract}

Keywords: Bronchial carcinoid; Massive ossification; Bone formation

\section{Introduction}

Carcinoid tumors of the lung comprise less than $5 \%$ of pulmonary neoplasms. ${ }^{1}$ Pulmonary carcinoid tumors are categorized depending on mitotic activity and necrosis (typical vs. atypical) and the location (central vs. peripheral). ${ }^{2}$ Atypical carcinoid tumors account for 10 to $20 \%$ of pulmonary carcinoids. ${ }^{3}$ The incidence of lymph node metastases in atypical carcinoids is estimated to be $70 \%$ versus $5 \%$ in typical carcinoid tumors, which points towards a less favorable prognosis for atypical carcinoid and requires more aggressive therapy. Surgical resection is the treatment of choice, with an excellent ten year survival post-surgery (up to $90 \%)^{4}$

Carcinoid tumors may show calcification and/or ossification, but massive ossification is rare. ${ }^{5}$ We report a case of a middle aged male with an atypical bronchial carcinoid with massive ossification, who was diagnosed with a neuroendocrine neoplasm preoperatively and underwent surgical resection of the tumor

\section{Case Presentation}

A 47-year-old Caucasian male prison inmate presented with unexplained fatigue, shortness of breath, fever, chronic cough productive of clear sputum, and weight loss of 12 lbs. over a 3-month period. He had a past medical history of 30 pack-years of smoking. The chest X-ray revealed complete opacification of the right hemithorax with collapse of the middle and lower lobes and midline shift towards the right side (Figure 1).

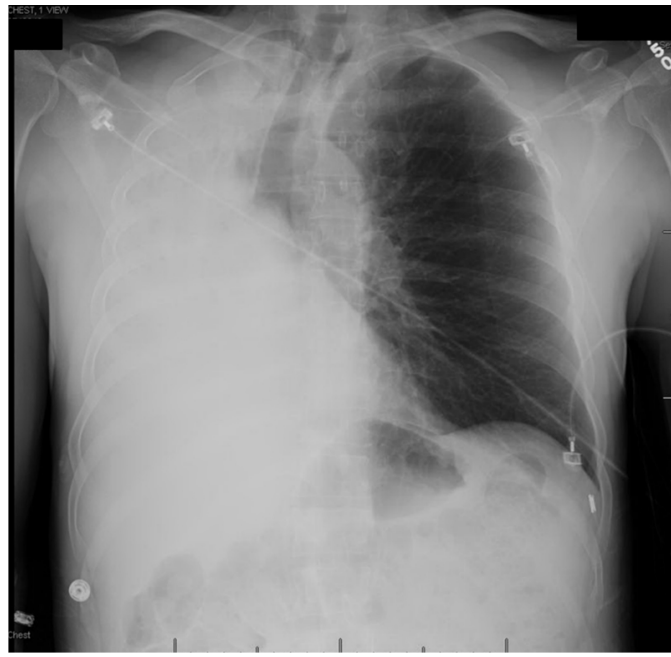

Figure 1: X-ray showing right hemithorax opacification with midline shift to the right side.

A CT scan with contrast showed a calcified right lung mass measuring $6 \mathrm{~cm}$ in greatest dimension that appeared to be arising from the right mainstem bronchus. Bronchoscopy showed a whitish-gray endobronchial lesion (Figure 2) occluding the lumen of the right mainstem bronchus and causing right lung atelectasis.

Corresponding author: Mohamed Khalil; Department of Pathology, University of Texas Medical Branch, Galveston, Texas, USA.

Cite this article as: Khalil M, Eltorky M. Bronchial carcinoid with massive ossification: A case report and review of literature. Int J

Cancer Ther Oncol. 2016; 4(2):429. DOI: 10.14319/ijcto.42.9 


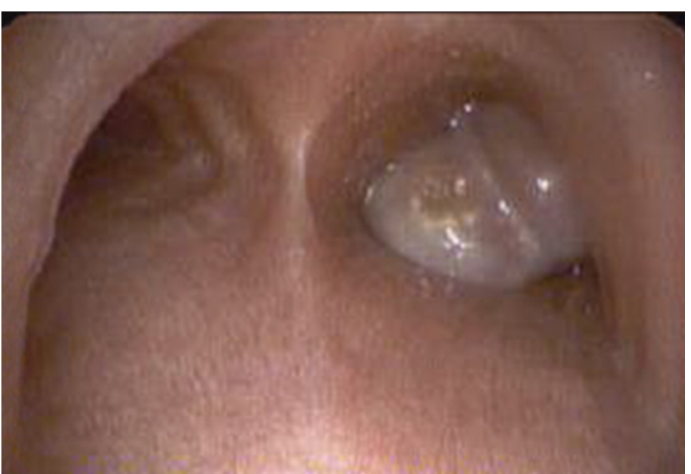

Figure 2: Bronchoscopy image showing whitish-gray endobronchial lesion grossly occluding the right mainstem bronchus.

Fine needle aspiration of the lesion was performed and revealed a well-differentiated neuroendocrine tumor; the neoplastic cells showed strong cytoplasmic immunoreactivity with antibodies to cytokeratin AE1/3, Synaptophysin, and Chromogranin A.

A right pneumonectomy was performed with minimal complications (Figure 3). Gross examination of the specimen revealed a 770 gram right lung, measuring 19 $\times 16 \times 11 \mathrm{~cm}$. An $8 \mathrm{~cm}$ in greatest dimension hard nodular mass was identified involving the right mainstem bronchus.

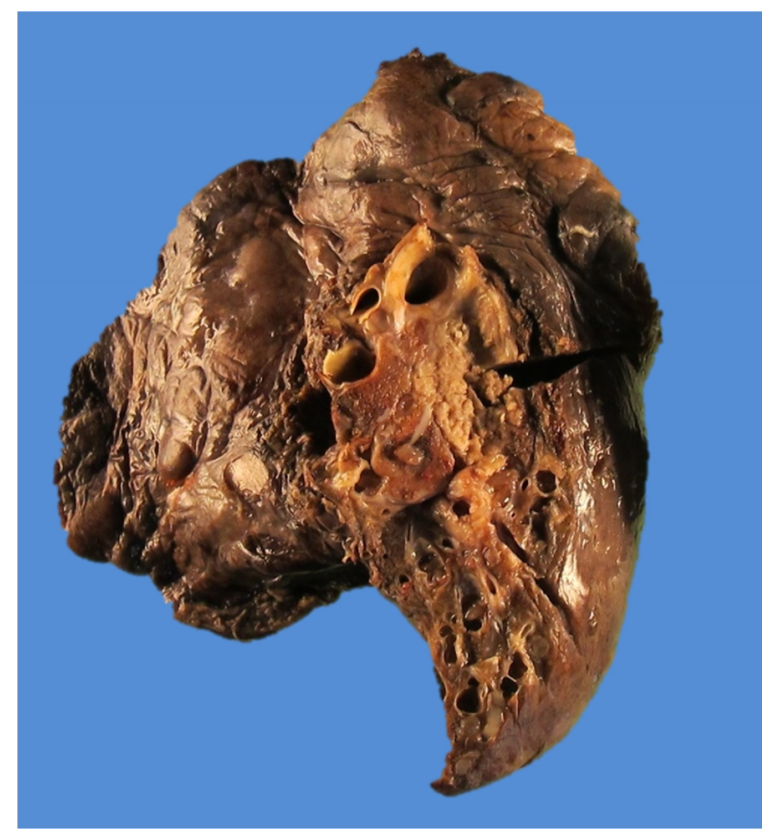

Figure 3: Right pneumonectomy specimen showing the hilar mass.

The mass (Figure 4) was hard in consistency, which required dissection utilizing a bone saw and decalcification. The cross-section of the mass revealed a tan cut surface with areas of reddish discoloration.

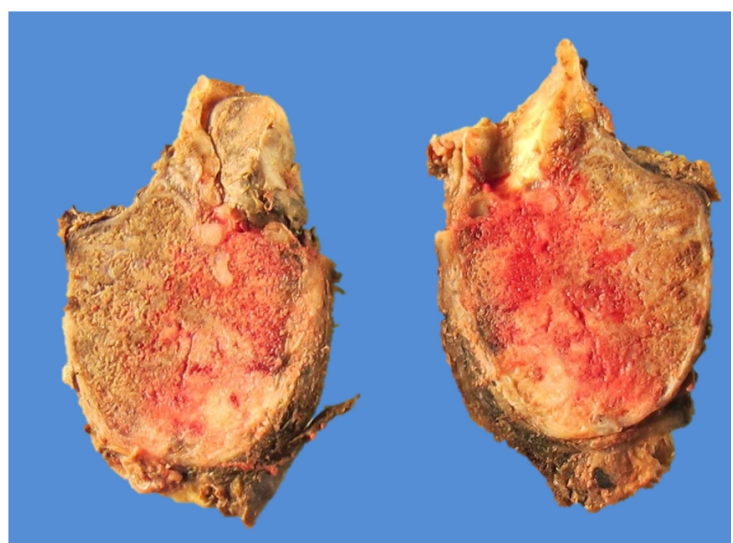

Figure 4: The ossified mass after dissection, showing a homogeneously hard cut surface.

Histologic examination of the mass revealed nests of monotonous small polygonal cells with fine eosinophilic cytoplasm, round nuclei with salt and pepper chromatin, and prominent nucleoli (Figure 5), separated with trabeculae of mature lamellar bone (Figure 6) and thin walled vascular structures with areas necrosis and mitosis (7 mitoses per 10 high power fields). The lung parenchyma showed massive organizing pneumonia and mucus plugging. Three hilar lymph nodes were identified that were positive for malignancy.

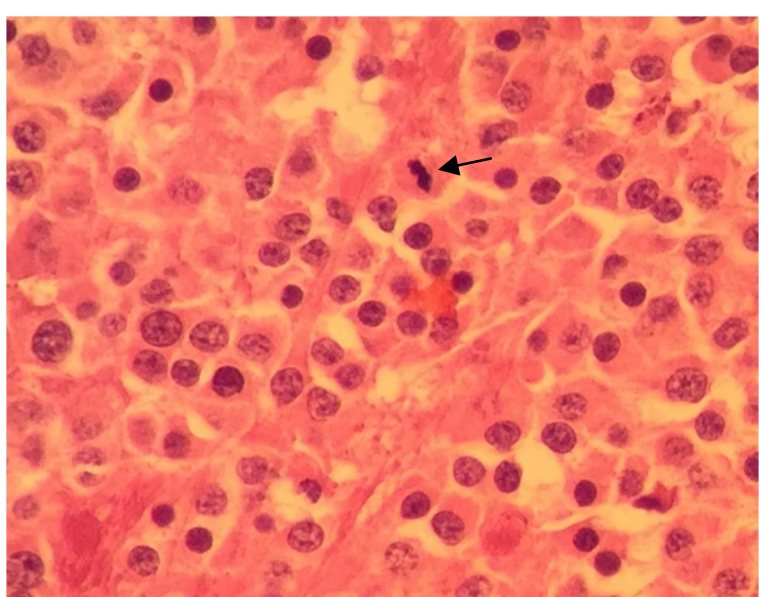

Figure 5: High magnification (400x) of the tumor showing monotonous cells with salt and pepper chromatin and prominent nucleoli. A mitotic figure (arrow) is located in the center of the field.

Immunohistochemical staining showed that the tumor cells were positive for Synaptophysin (Figure 7A) and Chromogranin A (Figure 7B), while negative for calcitonin. The Ki-67 proliferation index showed $10 \%$ of the cells with positive nuclear staining (Figure 7C). 


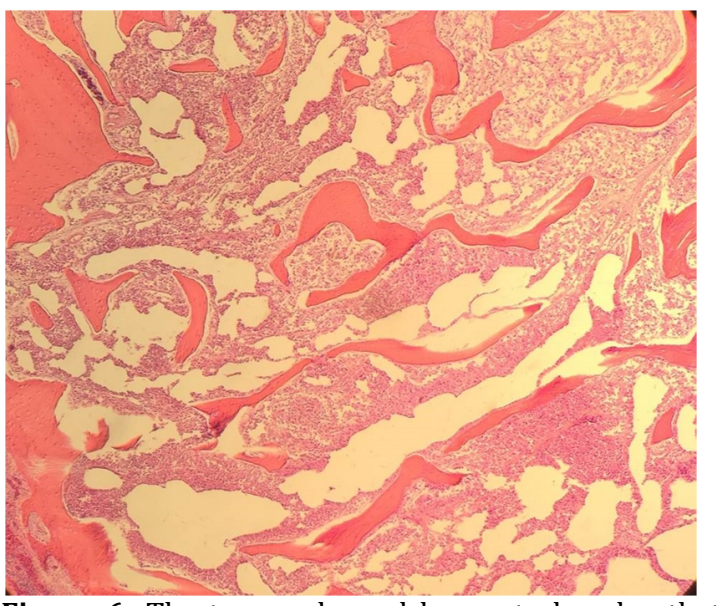

Figure 6: The tumor showed boney trabeculae that were widely spread and composed of mature lamellar ossified bone.

Table 1: Reported cases of ossifying bronchial carcinoid.

\begin{tabular}{|c|c|c|c|c|}
\hline Ref no. & Current case & $\mathrm{A}^{8}$ & $\mathrm{~B}^{5}$ & $\mathrm{C}^{6}$ \\
\hline Sex & $\mathrm{M}$ & $\mathrm{F}$ & $\mathrm{F}$ & $\mathrm{F}$ \\
\hline Age & 47 & 49 & 29 & 38 \\
\hline Size $(\mathrm{cm})$ & 8 & 1 & 4.7 & 4.5 \\
\hline Location & RML & LUL & LLL & LUL \\
\hline $\begin{array}{l}\text { Smoking } \\
\text { history }\end{array}$ & Yes & No & No & $\mathrm{N} / \mathrm{A}$ \\
\hline Metastasis & LN & No & $\mathrm{LN}$ & $\mathrm{N} / \mathrm{A}$ \\
\hline
\end{tabular}

\section{Discussion}

Our case presented as an atypical bronchial carcinoid that was centrally located, projecting into and obstructing the right mainstem bronchus, and causing lobar atelectasis of the right lung and pneumonia. This tumor exhibited an extremely rare feature of ossification.

Atypical carcinoid tumors are relatively common intermediate grade (grade IV) neuroendocrine pulmonary neoplasms ${ }^{7}$ that are differentiated from typical carcinoid tumors by showing a greater number of mitoses $(2-10$ per 10 high power fields) and/or necrosis, while the typical carcinoid tumors show less than 2 mitoses per 10 high power fields and no necrosis.

Occasional microscopic calcifications and /or ossification are seen in surgical/autopsy practice. ${ }^{8}$ Rare cases of gastric and peritoneal carcinoid with ossification have been described.

It is speculated that the mechanism of ossification is initiated by osteogenic factors secreted by the tumor cells that act on the surrounding stroma. ${ }^{9}$ It is proposed that the tumor cells produce an osteogenic factor, bone morphogenic protein-2 (BMP-2) which is a member of TGF-B super family.Osteocalcin that then acts on surrounding pluripotent mesenchymal stem cells (MSCs), transforming the MSCs into osteoblasts ${ }^{10}$ with subsequent bone formation.

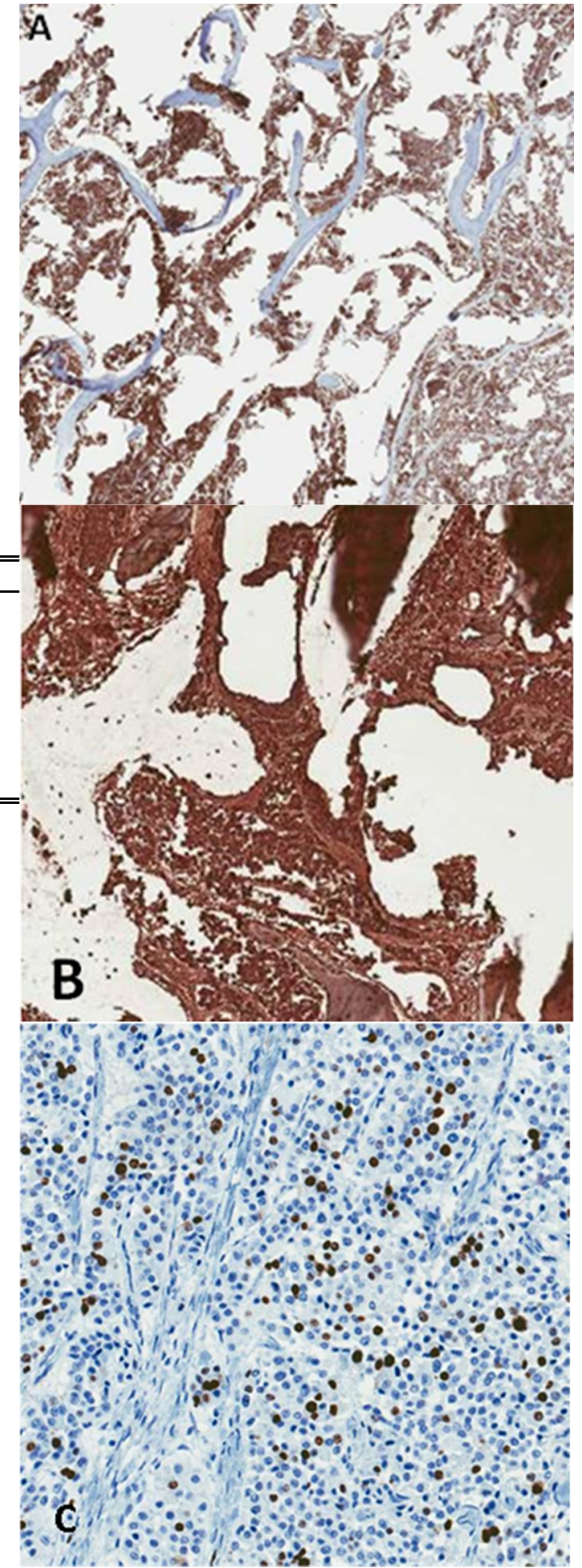

Figure 7: (A) The tumor cells in between the boney trabeculae exhibited positivity to Synaptophysin. (B) The tumor cells showed strong positivity for Chromogranin A. (C) Ki-67 staining showing $10 \%$ of the cells with positive nuclear staining. 
Osteocalcin is a marker for osteoblastic differentiation. Positive staining with this marker points towards the ossification of the surrounding stroma by the carcinoid tumor cells. Although the stain was not available to be demonstrated in our case, the confidence level that the tumor was forming bone remains high, given the size of the ossified portion of the tumor and its distribution.

\section{Conclusion}

In conclusion, this is a case of an atypical bronchial carcinoid that presented as a single calcified mass in a middle aged male with metastasis to the regional lymph nodes. The peculiar feature of this tumor is the formation of mature bone within a carcinoid tumor.

\section{Conflict of interest}

The authors declare that they have no conflicts of interest. The authors alone are responsible for the content and writing of the paper.

\section{References}

1. Davila DG, Dunn WF, Tazelaar HD, et al. Bronchial carcinoid tumors. Mayo Clin Proc. 1993;68(8):795-803.

2. Carter D. The neuroendocrine tumors of the lung, 1926-1998: some historical observations. Semin Diagn Pathol 2008; 25:154-65.

3. Chong S, Lee KS, Chung MJ, et al. Neuroendocrine tumors of the lung: clinical, pathologic, and imaging findings. Radiographics. 2006;26:41-57. discussion 57-48.
4. Blondal T, Grimelius L, Nou E, et al. Argyrophil carcinoid tumors of the lung. Incidence, clinical study, and follow-up of 46 patients. Chest. 1980;78(6):840-4.

5. Tsubochi H, Endo S, Oda Y, et al. Carcinoid tumor of the lung with massive ossification: report of a case showing the evidence of osteomimicry and review of the literature. Int J Clin Exp Pathol. 2013;6(5):957-61.

6. Troupin RH. Ossifying bronchial carcinoid. A case report. Am J Roentgeno Radium Ther Nucl Med. 1968;104(4):808-9.

7. Rosai J (Ed): Rosai \& Ackerman's Surgical Pathology, 10th Edan ., C.V. Mosby (Elsevier), St. Louis, 2011.

8. Tsubochi H, Endo S, Oda Y, et al. Carcinoid tumor of the lung with massive ossification: report of a case showing the evidence of osteomimicry and review of the literature. Int J Clin Exp Pathol. 2013;6(5):957-61.

9. Vanmaele L, Noppen M, Frecourt N, et al. Atypical ossification in bronchial carcinoid. Eur Respir J. 1990;3(8):927-9.

10. Pittenger MF, Mackay AM, Beck SC, et al. Multilineage potential of adult human mesenchymal stem cells. Science. 1999;284(5411):143-7. 